\title{
STELLAR OCCULTATHN MEASUREMENTS OF MOLECULAR OXYGEN IN THE LOWER THERMOSPHERE
}

\author{
P. B. HAYS \\ Departments of Aerospace Engineering, Meteorology and Oceanography, University of \\ Michigan, Ann Arbor, Michigan 48105, U.S.A. \\ and \\ R. G. ROBLE \\ National Center for Atmospheric Research, Boulder, Colorado 80302, U.S.A.
}

(Received in final form 8 August 1972)

\begin{abstract}
Stellar ultraviolet light near $1500 \AA$ is attenuated in the Earth's upper atmosphere due to strong absorption in the Schumann-Runge continuum of molecular oxygen. The intensity of stars in the Schumann-Runge continuum region has been monitored by the University of Wisconsin stellar photometers aboard the OAO-2 satellite during occultation of the star by the Earth's atmosphere. These data have been used to determine the molecular oxygen number density profile at the occultation tangent point. The results of 14 stellar occultations obtained in low and middle latitudes are presented giving the night-time vertical number density profile of molecular oxygen in the $140-200 \mathrm{~km}$ region. In general, the measured molecular oxygen number density is about a factor of 2 lower than the number densities predicted by the CIRA 1965 model. Also, the number density at a given height appears to decrease with decreasing solar activity. Measurements taken at low latitudes during the August 1970 geomagnetic storm showed a decrease in the molecular oxygen number density at a given height several days after the peak of the storm followed by a slow recovery to pre-storm densities.
\end{abstract}

\section{INTRODUCTION}

The first attempt at determining the molecular oxygen concentration in the upper atmosphere by u.v. absorption spectroscopy was made on a V-2 rocket experiment in 1949 (Friedman et al., 1951). The molecular oxygen concentration was obtained from the solar u.v. absorption measurements made at various altitudes by a spectrometer aboard the rocket. Since then, numerous rocket flights have been made to examine the molecular oxygen distribution and its variations, in addition to determining the u.v. spectra of the Sun (Byram et al., 1955; Kupperian et al., 1959; Jursa et al., 1963; Hall et al., 1963; Hinteregger et al., 1965; Week and Smith, 1968; Opal and Moos, 1969; Quessette, 1970; Brannon and Hoffman, 1971).

The molecular oxygen distribution in the altitude range 100-200 km has also been determined from mass spectroscopic measurements (Schaefer and Nichols, 1964; Nier et al., 1964; Hedin and Nier, 1966; Schaefer, 1968; Krankowsky et al., 1968; von Zahn and Gross, 1969). In addition to molecular oxygen, the other major and minor constituents of the upper atmosphere are likewise determined as a function of altitude during the rocket flight.

More recently, satellites have been used to determine the properties of the upper atmosphere from u.v. absorption measurements. The satellites have monitored the attenuation of solar u.v. radiation in various isolated wavelength intervals during occultation at orbital sunrise and sunset. These data have been used to retrieve the neutral air density (Thomas et al., 1965; Kreplin, 1965; Venables, 1967; Landin et al., 1965; Landin et al., 1967) and the molecular oxygen distribution in the lower thermosphere (Thomas and Norton, 1967; Norton and Warnock, 1968; Link, 1969; Stewart and Wildman, 1969; Lockey 
et al., 1969; Reid and Withbroe, 1970; May, 1971; Roble and Norton, 1972). These measurements, however, are limited only to sunrise and sunset.

Hays and Roble (1968a) suggested that u.v. stars may be used as source for occultation measurements to determine the night-time distribution of molecular oxygen and ozone in the lower thermosphere and upper mesosphere. Their calculations showed that in the spectral region near $1500 \AA$ attenuation is primarily due to absorption by molecular oxygen, and that Rayleigh scattering and absorption by other minor constituents can be neglected.

During the past few years, we have used the Orbiting Astronomical Observatory (OAO2) to obtain u.v. stellar occultation data in various spectral intervals. These data have been used to obtain the night-time molecular oxygen number density and neutral gas temperature in the lower thermosphere from about $140-200 \mathrm{~km}$. The purpose of this paper is to describe the experimental technique and discuss the results which were obtained during quiet and disturbed geomagnetic conditions.

\section{EXPERIMENTAL TECHINIQUE}

The general details of the stellar occultation technique (Fig. 1) have been described by Hays and Roble (1968a, b), Hays et al. (1972) and Roble and Hays (1972). Here we describe the specifics of the occultation measurements made by the OAO-2 satellite.

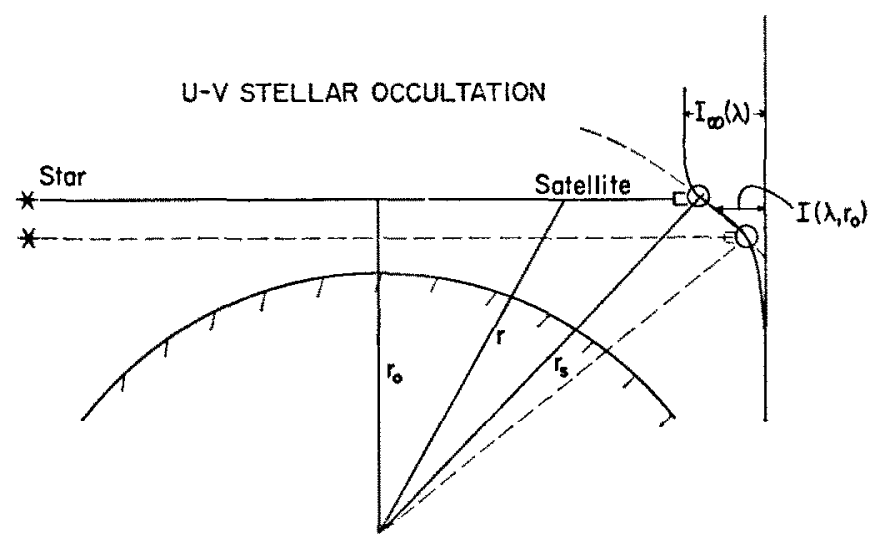

Fig. 1. Geometry of stellar occultation, $r_{0}=r_{i}$.

The OAO-2 satellite has one 16 in. dia u.v. telescope, four 8 in. dia u.v. telescopes, and an u.v. spectrometer having a resolution of approximately $5 \AA$. The University of Wisconsin optical package, used in conjunction with the telescopes, consists of a series of u.v. filters which are used for stellar photometry. Filter (4-1) shown in Fig. 2 has a broadband transmission function centered near $1450 \AA$ in the Schumann continuum region of molecular oxygen. This filter was used to obtain the molecular oxygen distributions from the stellar occultation measurements. The detection systems of the u.v. telescopes have a variable time integration range. The data shown in Fig. 4, which is typical of the high data rate occultation scans, has approximately a $1.5 \mathrm{~km}$ altitude resolution between data points.

Prior to occultation of the star by the Earth, an unattenuated u.v. spectrum of the star is obtained from the spectrometer. As an example, the spectrum for a typical bright u.v. star is shown in Fig. 3 for the wavelength region of the molecular oxygen u.v. filter. Although only a measurement of the relative change of the u.v. stellar intensity is required during occultation (Hays and Roble, 1968a), the spectral distribution of the star's energy 


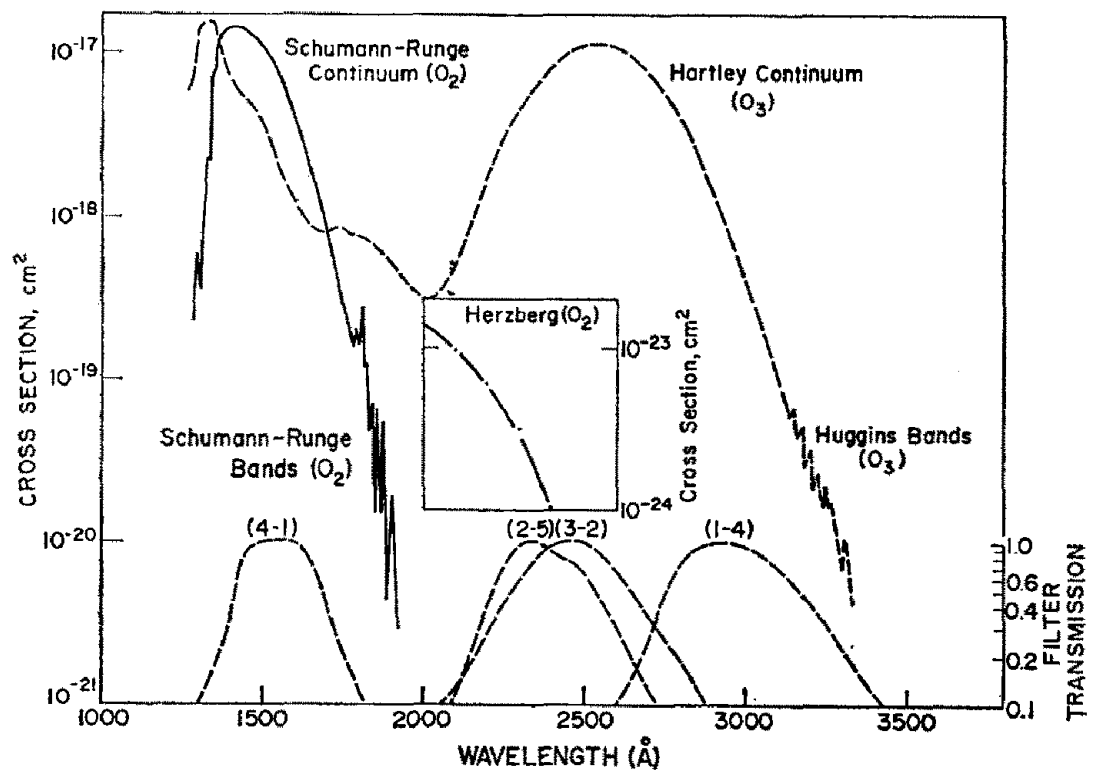

Fig. 2. ABsorption cross sEctions for MOLECUL,AR OXYGEN AND OZONE IN THE SPECTRAL REGION EXTENDING FROM 1000 TO $3500 \AA$. DASHED CURVES ARE THE O.A.O. STELLAR PHOTOMETER FILTER TRANSMISSION CURVES USED IN THIS STUDY.

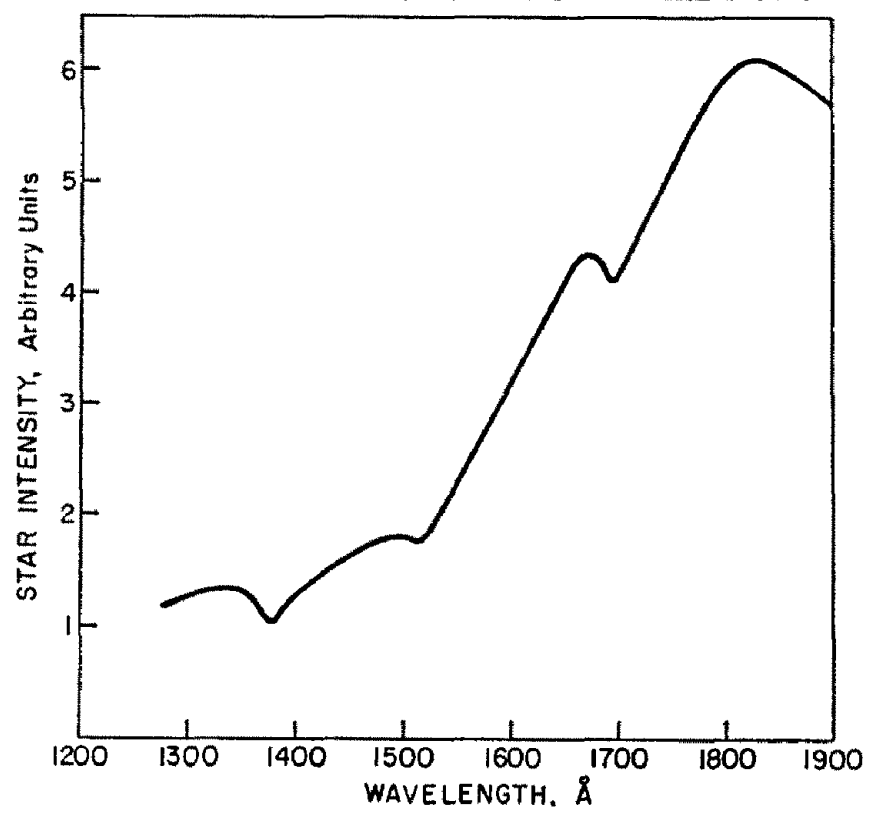

Fig. 3. TYPical spectrum of a star used as an OCCULtation LIGHT SOURCE.

flux is required to determine the transmission through the broadband filter. Thus, a detailed stellar spectrum covering the spectral passband of the filter is necessary for data reduction.

A schematic diagram of an occultation of a star by the Earth is shown in Fig. 1. The satellite acquires the star in its telescopes prior to occultation above the absorbing atmosphere. As the satellite moves in its orbit, the source is ultimately occulted by the Earth's atmosphere and the geometry at two satellite positions is illustrated schematically in Fig. 1. 
P. B. HAYS and R. G. ROBLE

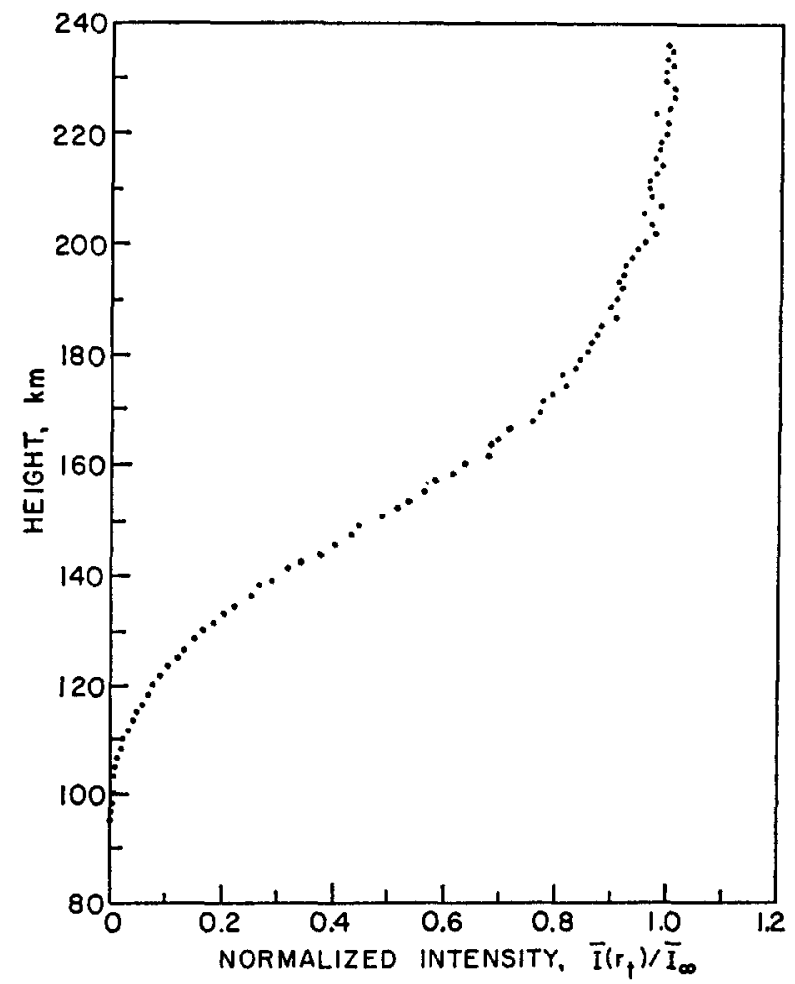

Fig. 4a. Normalized steliar intensity as a fUNCTION OF tANGent Ray heIGHT DURING OCCULTATION.

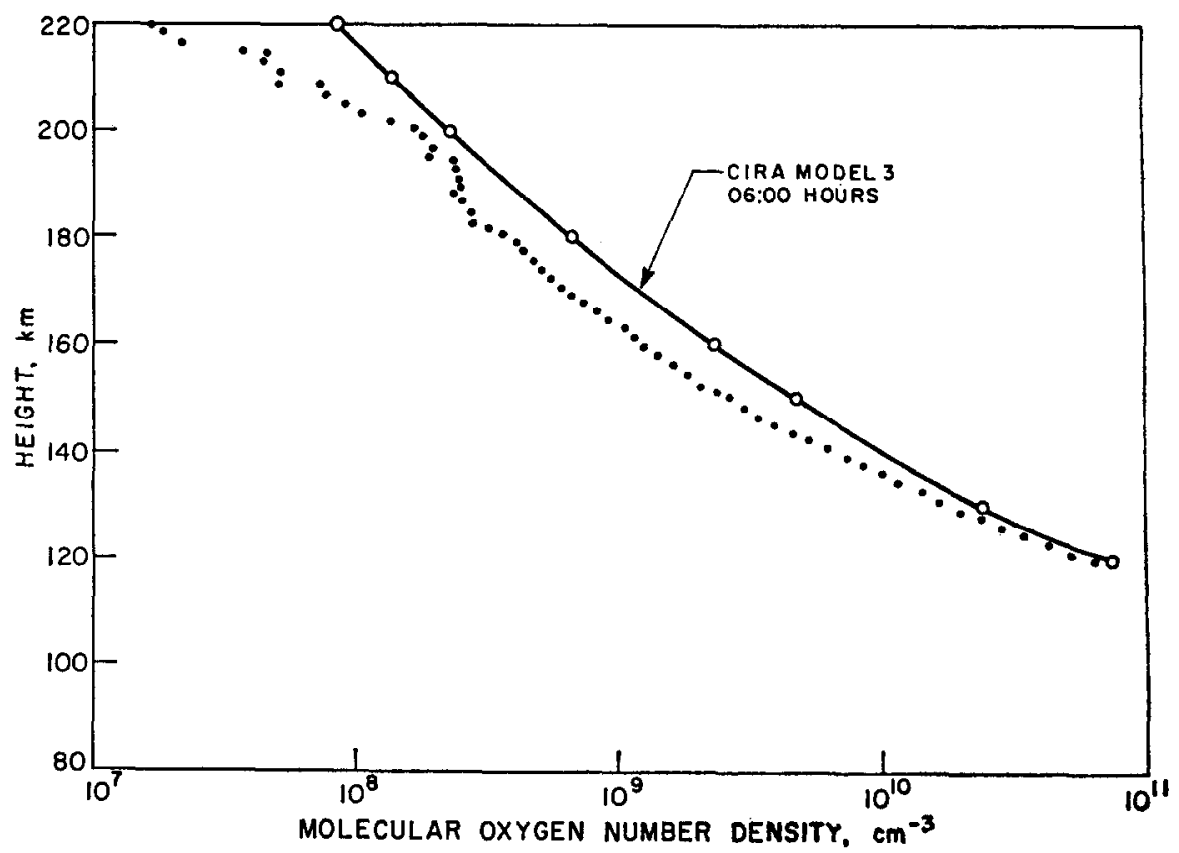

Fio. 4b. Molecular oxygen density vs. height from data shown in Fig. $4 a$. 


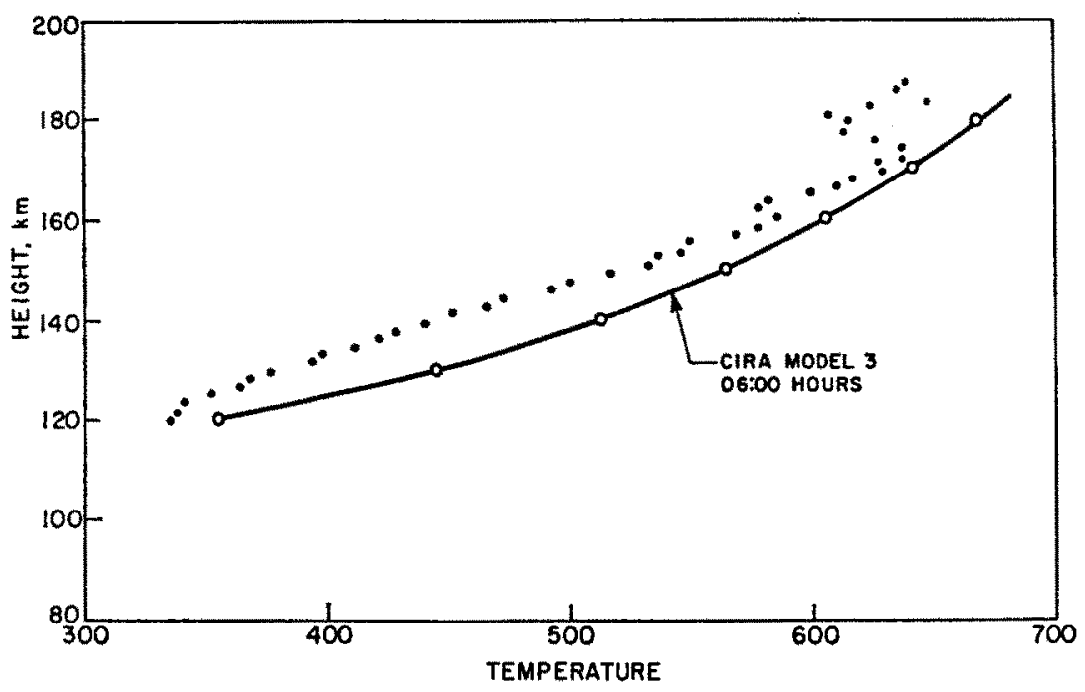

FIG. 4c. TEMPERATURE YS. HEIGHT DEDUCED FROM THE MOLECULAR OXYGEN NUMBER DENSITY DATA SHOWN IN FIo. 4b ASSUMang DLFFUSIVE BQUILIBRTUM.

The intensity of the star is measured as a function of time during occultation by the Earth. By knowing the satellite position as a function of time and the star's position, we can relate the star's intensity to the tangent ray height of the star during occultation. By also knowing the position of the star, satellite, and the time, we obtain from geometry the geographic position of the tangent ray point.

The intensity data are normalized to the intensity of the star above the atmosphere and the normalized data are related to the tangential column number density of the absorbing species, here $\mathrm{O}_{2}$, by the integral relationships expressing Beer's law

$$
I\left(r_{t}\right) / \overline{\mathbf{I}}_{\infty}=\left\{\int_{0}^{\infty} T(\lambda) I_{\infty}(\lambda) \exp \left(-\sigma_{0_{2}}(\lambda) N_{0_{2}}\left(r_{t}\right) \mathrm{d} \lambda\right) \iint_{0}^{\infty} T(\lambda) I_{\infty}(\lambda) \mathrm{d} \lambda\right\}^{-1}
$$

where from the geometry in Fig. 1, assuming a spherically stratified atmosphere

$$
N_{0},\left(r_{t}\right)=2 \int_{r_{t}}^{\infty} \frac{n_{0_{2}}(r) r \mathrm{~d} r}{\sqrt{r^{2}-r_{t}^{2}}}
$$

Here $I\left(r_{t}\right)$ is the photometer count rate at tangent ray height $r_{t}$ and $I_{\infty}$ is the photometer count rate of the stellar signal above the atmosphere. $T(\lambda)$ is the filter transmission and $I_{\infty}(\lambda)$ is the intensity of the star at wavelength $\lambda$ above the atmosphere determined by the spectrometer; $\sigma_{0},(\lambda)$ is the absorption cross-section of molecular oxygen shown in Fig. 2 (Ditchburn and Young, 1962; Hudson et al., 1969; Ackerman, 1970) and $N_{0_{2}}\left(r_{t}\right)$ is the tangential column number density of molecular oxygen at tangent ray radius $r_{t}$; and $n_{\mathrm{O}_{3}}(r)$ is the local number density at the radius $r$.

Molecular oxygen is the sole absorbing species in the wavelength interval determined by filter 41, therefore the normalized intensity data are converted to tangential column number density data using Equation (1). The basic measurements are thus converted to data giving the tangential column number density of molecular oxygen as a function of tangent ray height. Equation (2) for the tangential column number density is the Abel integral 
equation (cf. Hays and Roble, 1968a, b) which is inverted to obtain the local number density at the tangent ray point assuming spherical symmetry,

$$
n_{\mathrm{O}_{2}}(r)=\frac{1}{2 \pi} \frac{\mathrm{d}}{\mathrm{d} r}\left\{\int_{r}^{\infty} \frac{r}{r_{t}} \frac{N_{\mathrm{O}_{2}}\left(r_{t}\right) \mathrm{d} r_{t}}{\sqrt{r_{t}{ }^{2}-r^{2}}}\right\}
$$

The actual numerical techniques for accomplishing this inversion are described in detail in a paper by Roble and Hays (1972).

The neutral gas temperature is derived by assuming diffusive equilibrium above $130 \mathrm{~km}$ for the $\mathrm{O}_{2}$ number density. Thus,

$$
T_{\mathrm{O}_{2}}(r)=\frac{m_{\mathrm{O}_{2}}}{k n_{\mathrm{O}_{2}}(r)} \int_{r}^{\infty} g\left(r^{\prime}\right) n_{\mathrm{O}_{2}}\left(r^{\prime}\right) \mathrm{d} r^{\prime}
$$

where $m_{\mathrm{O}_{\mathrm{z}}}$ is the mass of molecular oxygen, $k$ is Boltzmann's constant, and $g$ is the acceleration of gravity.

\section{RESULTS}

A relatively large number of absorption profiles were obtained during the time period extending from January 1970 to August 1971. Of these, command errors and tracking errors have caused serious question about many profiles. The final result of carefully selecting only those profiles where altitude is accurately known and where there are no command interrupts during the occultation yields 14 useful occultations. Of these, approximately 6 are in geomagnetically quiet periods and one series of 8 profiles was obtained during the magnetic storm of August 1970. Almost all of these profiles were obtained in low. latitudes due to the low inclination of the orbital plane of the OAO-2 satellite. In addition to the molecular oxygen occultation scans, measurements were also made with a filter located in the Hartley continuum of ozone. (Filters 2-5 and 3-2 shown in Fig. 2). A single nighttime ozone number density profile was presented by Hays et al. (1973) and the results of the other scans are presented by Hays and Roble (1973).

(a) Molecular oxygen profiles during geomagnetically quiet periods

The geographic position, date, and local time of all of the scans analyzed are given in Table 1. Six of these were taken during geomagnetically quiet conditions. The normalized intensity measurements obtained on orbit 8884 on 17 August 1970 are shown in Fig. 4a. In Figs. $4 \mathrm{~b}$ and $4 \mathrm{c}$ the retrieved molecular oxygen number density and temperature are shown and they are compared with CIRA 1965 (model 3,06:00 hr.). In general, the retrieved molecular oxygen number density distribution in the $140-180 \mathrm{~km}$ region is about a factor of two lower than the number densities predicted by the CIRA 1965 model atmosphere at the same local time as the measurements. The composite of all of our quiet time data is shown in Fig. 5 along with the results of Krankowsky et al. (1968), Weeks and Smith (1968), and Roble and Norton (1972). The envelope encompassing the ozone number density profiles obtained from Hays and Roble (1972) and the molecular oxygen number density given by the mean CIRA 1965 atmosphere are also shown. The small number of stellar occultation profiles makes detailed seasonal variations difficult to discern. However, there does appear to be a marked decrease in the molecular oxygen number density corresponding to the decrease in solar activity during the period from the beginning of 1970 to late 1971. The monthly mean of the solar F10.7 flux during this period decreased from 153 to $120\left(\times 10^{-22}\right) \mathrm{W} \mathrm{cm}^{-2}$. The daily solar F10.7 emission for each of the individual 
TABLE 1

\begin{tabular}{|c|c|c|c|c|c|c|c|c|}
\hline Orbit & Date & \multicolumn{2}{|c|}{ Universal time } & \multicolumn{2}{|c|}{ Local time } & $\begin{array}{c}\text { Long.* } \\
\text { (deg) }\end{array}$ & $\begin{array}{l}\text { Lat. } \\
\text { (deg) }\end{array}$ & $\begin{array}{c}\text { Daily solar } \\
\text { F10.7 emission } \\
\left(\times 10^{-32} \mathrm{~W} \mathrm{~cm}^{-2}\right)\end{array}$ \\
\hline 5778 & $1 / 13 / 70$ & 5 & 28 & 23 & 52 & -84 & 48 & $172 \cdot 9$ \\
\hline 8884 & $8 / 17 / 70$ & 4 & 55 & 5 & 55 & 15 & 4 & $151 \cdot 6$ \\
\hline 8898 & $8 / 18 / 70$ & 4 & 19 & 5 & 51 & 23 & 9 & $149 \cdot 0$ \\
\hline 8913 & $8 / 19 / 70$ & 5 & 22 & 5 & 54 & 8 & 11 & $145 \cdot 4$ \\
\hline 8942 & $8 / 21 / 70$ & 5 & 55 & 4 & 27 & -22 & 24 & $142 \cdot 8$ \\
\hline 8943 & $8 / 21 / 70$ & 7 & 35 & 4 & 23 & -48 & 24 & $142 \cdot 8$ \\
\hline 8957 & $8 / 22 / 70$ & 6 & 58 & 4 & 22 & -39 & 25 & $141 \cdot 7$ \\
\hline 8971 & $8 / 23 / 70$ & 6 & 20 & 4 & 44 & -24 & 27 & $146 \cdot 2$ \\
\hline 8985 & $8 / 24 / 70$ & 5 & 45 & 4 & 13 & -23 & 24 & $140 \cdot 2$ \\
\hline 8986 & $8 / 24 / 70$ & 7 & 25 & 4 & 13 & -48 & 24 & $140 \cdot 2$ \\
\hline 9000 & $8 / 25 / 70$ & 6 & 47 & 5 & 17 & -32 & 27 & 136.5 \\
\hline 10902 & 1) $4 / 71$ & 13 & 29 & 22 & 38 & -223 & -16 & $140 \cdot 2$ \\
\hline 11795 & $3 / 7 / 71$ & 15 & 59 & 0 & 33 & 128 & -34 & $105 \cdot 2$ \\
\hline 14580 & $9 / 17 / 71$ & 6 & 22 & 1 & 50 & -68 & 26 & 116.5 \\
\hline
\end{tabular}

* Measured positive eastward from Greenwich.

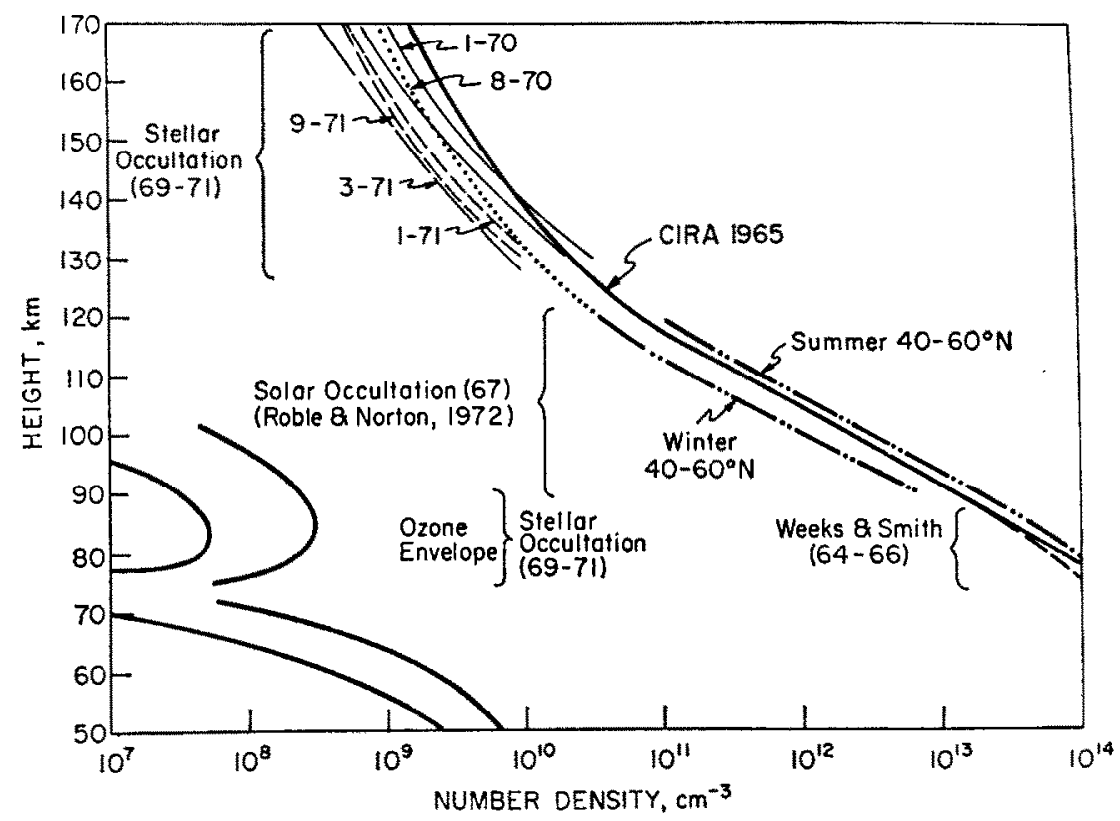

Fig. 5. COMPOSITE MOLECULAR OXYGEN DENSTTY RESULTS FOR QUIET TIMES. .... Krankowsky et al., 1968.

scans are given in Table 1. The apparent decrease in the thermospheric molecular oxygen at a fixed height probably implies that there is a general decrease in the altitude of the constant pressure surface at the base of the thermosphere as well as a decrease in the thermospheric temperature. This suggests a solar cycle influence in the lower thermosphere.

(b) Molecular oxygen profiles during geomagnetically disturbed periods

A series of observations was obtained during the magnetically disturbed period at the and of August 1970. These data are presented in Fig. 6 where density and temperature at 
fixed heights are shown as a function of time. For comparison, we show the daily sum of magnetic $K_{p}$ index on this same figure and give the latitude and longitude of the tangent ray point and local time of each occultation scan in Table 1 . We note the marked decrease in the molecular oxygen number density following the storm at a time when the temperature was significantly enhanced. This is obviously in disagreement with the concept of a diffusively stable atmosphere. The decrease in the molecular oxygen density is apparently due to

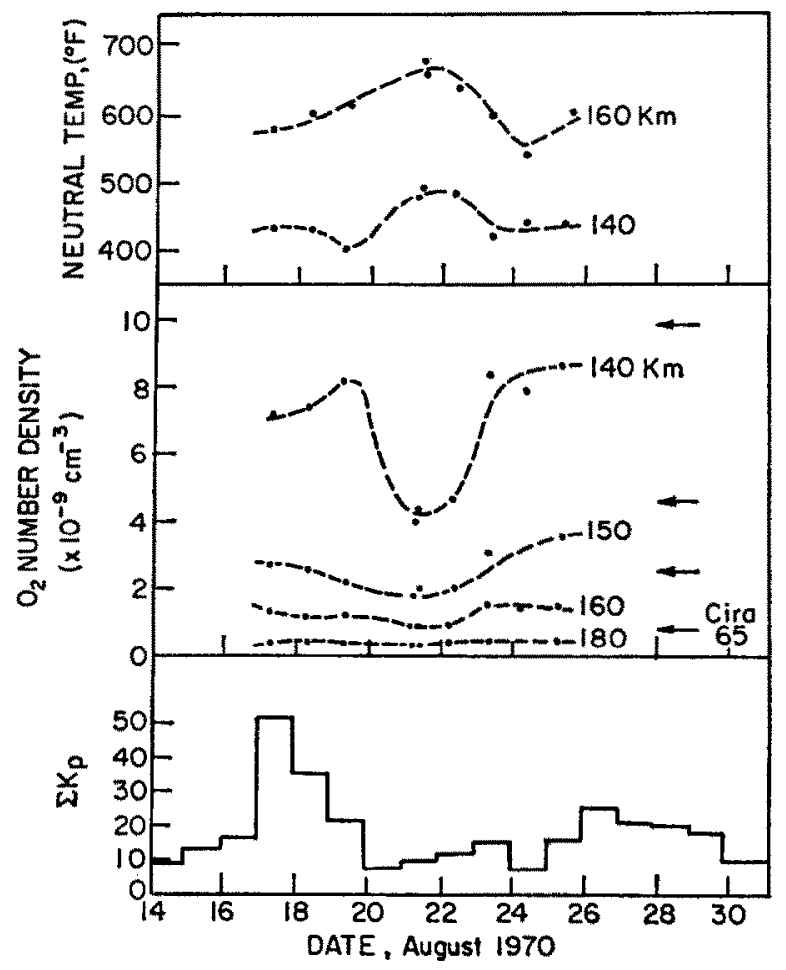

FIo. 6. MOLECULAR OXYOEN DENSITY AND TEMPERATURE VARIATIONS DURING THE MAGNETIC STORM OF AUGUST 1970.

the existence of a global-scale circulation system which upwells over the polar regions and subsides in the equatorial zone. Such a large horizontal scalc overturning causes air with more atomic than molecular oxygen to move downward over the equator resulting in a change in the composition of the lower thermosphere. This result is consistent with the observation that energy deposited in the polar thermosphere is redistributed globally resulting in a global thermospheric temperature enhancement at low latitudes following a large magnetic storm (Hays et al., 1972b). The daily solar F10.7 emission for the days on which occultation scans were made is given in Table 1. During the period the daily solar F10.7 emission decreased from 151.6 to $136.5\left(\times 10^{-22} \mathrm{~W} \mathrm{~cm}^{-2}\right)$. However, the molecular oxygen number density during this period first decreased, but then returned to pre-storm levels several days after the storm. This behavior also suggests an atmospheric response different from that expected from short term solar e.u.v. changes. 


\section{SUMMARY}

The stellar occultation technique for measuring molecular oxygen in the Earth's thermosphere has demonstrated the following general behavior: (a) Thermospheric molecular oxygen decreases with decreasing solar activity. This may result from a general cooling of the lower thermosphere in addition to the cooling observed in the upper thermosphere.

(b) Magnetic storms result in strong global circulation systems which upwell in the polar regions and sink in equatorial regions. This results in a temporary decrease in the molecular constituents in the equatorial thermosphere.

Acknowledgement-We wish to acknowledge the support of Grant NGR 23-005-360, and NASA Contract Nas 1 9958. The National Center for Atmospheric Research is sponsored by the National Science Foundation. We wish to acknowledge the helpful support of Dr. Houk, and the O.A.O. Wisconsin and NASA experimental team.

\section{REFERENCES}

Brannon, P. J. and Hofrman, J. M. (1971). Molecular oxygen density measurements from 80 to 140 kilometers. J. geophys. Res. 76, 4630.

Byram, E. T., ChubB, T, A. and Friedman, H. (1955). Dissociation of oxygen in the upper atmosphere. Phys. Rev. 98, 1594.

CIRA, Cospar International Reference Atmosphere, (1965). $312 \mathrm{pp}$. North-Holland, Amsterdam.

Ditchiurn, R. W. and Youna, P. A. (1962). Absorption of molecular oxygen between 1850 and $2500 \AA$ J. atmos. terr. Phys. 24, 127.

FrIedman, H., Lichtman, S. W. and BYram, E. T. (1951). Photon counter measurements of solar X-rays and extreme ultra-violet light. Phys. Rev. 83, 1025.

HALL, L. A., SCHWEIZER, W. and HINTEREGGER, H. E. (1963). Diurnal variation of the atmosphere around 190 kilometers derived from solar extreme ultraviolet absorption measurements. J. geophys. Res. 68, 6413.

HAYs, P. B. and RoBLe, R. G. (1968a). Stellar spectra and atmospheric composition, J. atmos. Sci. 25, 1141.

HAYs, P. B. and RoBle, R. G. (1968b). Atmospheric properties from the inversion of planetary occultation data. Planet. Space Sci. 16, 1197.

HAYs, P. B., RoBle, R. G. and Shak, A. N. (1972). Terrestrial atmospheric composition from stellar occultations. Science 176, 793.

Hays, P. B., Jones, R. and ReEs, M. H. (1973). Auroral heating and the composition of the neutral atmosphere. Planet. Space Sci. in press.

HAYs, P. B. and ROBLE, R. G. (1973). Observations of mesospheric ozone at low latitudes. Planet. Space Sci., 21, 273.

HedIN, A. E. and Nrer, A. O. (1966). A determination of the neutral composition, number density, and temperature of the upper atmosphere from 120 to 200 kilometers with rocket-borne mass spectrometers. J. geophys. Res. 71, 4121.

HiNTEREGGer, H. E., HALL, L. A. and SchmidTKE, G. (1965). Solar XUV radiation and neutral particle distribution in July 1963 thermosphere. Space Res. $V, 1175$.

Hudson, R. D., CARTER, V. C. and Breig, E. L. (1969). Photodissociation in the Schumann-Runge Band system of $\mathrm{O}_{2}$ : Laboratory measurements and atmospheric effects. J. geophys. Res. 74, 4079.

JURSA, A. S., Nakamura, M. and TANaKA, Y. (1963). Molecular oxygen distribution in the upper atmosphere. J.geophys. Res. 68, 6145.

KranKowsKy, D., KASPRZAK, W. T. and NIER, A. O. (1968). Mass spectrometric studies of the composition of the lower thermosphere during summer 1967. J. geophys. Res. 73, 7291.

KREPLIN, R. W. (1965). NRL solar radiation monitoring satellite: Description of instrumentation and preliminary results. Space Res. $V, 951$.

Kupperian, J. E., JR., Byram, E. T. and Friedman, H. (1959). Molecular oxygen densities in the mesosphere at Fort Churchill. J. atmos. terr. Phys. 16, 174.

LANDINI, M., Russo, D. and TAGliaferRI, G. L. (1965). Atmospheric density in the 120-190 Km region derived from the X-ray extinction measured by the U.S. Naval Research Laboratory Satellite 1964-01-D. Nature 206, 173.

LANDIN, M., Russo, D. and TAgliaferRI, G. L. (1967). Atmospheric density measured by the attenuation of the solar X-rays monitored on the NRL 1965-16D satellite. Icarus 6, 236.

LiNk, R. (1969). Eclipse in Astronomy, 271 pp. Springer, New York.

LOCKEY, G. W., HoRTON, B. H. and ROFE, B. (1969). Satelite measurement of upper atmospheric molecular oxygen density. Nature, London 223, 387. 
MAY, B. R. (1971). A method of determining the density of thermospheric gases from measurements of solar ultra-violet light absorption at grazing-ray and near-vertical incidence. Planet. Space Sci. 19, 27.

Nier, A. O., Hofrman, J. H., Johnson, C. Y. and Holmes, J. C. (1964). Neutral composition of the atmosphere in the 100 to 200 kilometer range. J. geophys. Res. $69,979$.

NoRTON, R. B. and WARNOCK, J. M. (1968). Seasonal variation of molecular oxygen near 100 kilometers. J. geophys. Res. 73, 5798 .

Opal, C. B. and Moos, H. W. (1969). Night-time molecular oxygen densities in the $100-$ to $130-\mathrm{km}$ region from Schumann-Runge absorption. J. geophys. Res. 75, 788.

QUESSETTE, J. A. (1970). On the measurement of molecular oxygen concentration by absorption spectroscopy. J. geophys. Res. $75,839$.

REID, R. H. G. and WITHBRoE, G. L. (1970). The density and vibrational distribution of molecular oxygen in the lower thermosphere. Planet. Space Sci. 18, 1255.

RoBle, R. G. and NORTON, R. B. (1972). Thermospheric molecular oxygen from solar EUV occultation measurements. J. geophys. Res. $77,3524$.

ROBLE, R. G. and HAYS, P. B. (1972). A technique for recovering the vertical number density profile of atmospheric gases from planetary occultation data. Submitted to Planet. Space Sci. 20, 1727.

SCHAEFER, E. J. and NiCHOLS, M. H. (1964). Neutral composition obtained from a rocket-borne mass spectrometer. Space Res. IV, 205.

SCHAEFER, E. J. (1968). Temperature and composition of the lower thermosphere obtained from mass spectrometer measurements. Space Res. VIII, 959.

SteWART, K. H. and Wildman, P. J. L. (1969). Preliminary results of molecular oxygen observations from Ariel III satellite. Proc. $R$. Soc. A311, 591.

Thomas, L. and Norton, R. B. (1967). Absorption of solar X-rays and density changes between 140 and 160 kilometers. J. geophys. Res. $72,5552$.

Thomas, L., Venables, F. H. and Williams, K. M. (1965). Measurements of solar X-ray fluxes by the U.S. Naval Research Laboratory Satellite 1965-01-D.

VENABLES, F. H. (1967). Solar X-rays in the wavelength band 44-60A observed by the U.S. NRL satellite 1965-16D and atmospheric optical densities deduced from these observations. Planet. Space Sci. 15, 681.

voN ZAHN, U. and GRoss, J. (1969). Mass spectrometric investigation of the thermosphere at high latitudes. J. geophys. Res. 74, 4055 .

WeEKs, L. H. and SMITH, L. G. (1968). Molecular oxygen concentrations in the upper atmosphere by absorption spectroscopy. J. geophys. Res. 73,4835 . 